\title{
Capítulo
} 1

\section{Avanços da Aprendizagem Colaborativa com Suporte Computacional na Educação 4.0}

\author{
Juliana Baptista dos Santos França, Angélica Fonseca da Silva Dias e \\ Marcos Roberto da Silva Borges
}

\begin{abstract}
The new technological and collaborative resources that everyone is exposed daily have shown great potential for inclusion, sociability, information sharing, and knowledge construction. Any group today collaborates through popular tools like WhatsApp, Zoom, Google Drive, and Social Media. If many advances have occurred from a technological standpoint, challenges and opportunities are still perceived in the application of this evolution in Education, especially in Computer-Supported Collaborative Learning (CSCL). It is known that an individual learns more and better when he is in a welcoming, representative, and collaborative environment. Therefore, collaborative learning is expected to yield good social and academic results. However, CSCL initiatives are known to be unsuccessful. Much of this failure is associated with a lack of planning of the collaboration strategies needed to accomplish the task. This is the time to move forward in the era of Education 4.0 as professionals and an educational research community, more specifically in CSCL. This course discusses the principles of CSCL and the innovation strategies employed in Education 4.0.
\end{abstract}

\section{Resumo}

Os novos recursos tecnológicos e colaborativos a que cada indivíduo é exposto diariamente têm apresentado grande potencial para inclusão, sociabilidade, compartilhamento de informação e construção de saberes. Qualquer grupo hoje colabora por meio de ferramentas populares como WhatsApp, Zoom, Google Drive, e Mídias Sociais. Se muitos avanços ocorreram do ponto de vista tecnológico, ainda se percebem desafios e oportunidades para aplicar essa evolução na Educação, especialmente na Aprendizagem Colaborativa mediada por Computador (CSCL Computer Supported Collaborative Learning). Sabe-se que um individuo aprende mais $e$ melhor quando se encontra em um ambiente acolhedor, de representatividade $e$ colaboratividade. Logo, espera-se que a aprendizagem colaborativa renda bons resultados sociais e acadêmicos. No entanto, são conhecidas iniciativas de aprendizagem 
colaborativa mediada por computador (CSCL) que não apresentaram sucesso. Muito desse fracasso está associado a falta de planejamento das estratégias de colaboração necessárias para o cumprimento de uma tarefa. Este é o momento para avançarmos na era da Educação 4.0 enquanto profissionais e comunidade de pesquisa em educação, mais especificamente em CSCL. Este capitulo discute os princípios de CSCL, o planejamento da colaboração voltado ao ensino e as estratégias de inovação empregadas na Educação 4.0.

\subsection{Introdução}

A Aprendizagem Colaborativa tem sido defendida por educadores e constitui-se de um conjunto de métodos e técnicas de aprendizagem em grupo, no qual a responsabilidade pela aprendizagem de cada indivíduo é compartilhada com os demais membros do grupo. Esta prática de interação social, juntamente com a participação ativa, fortalece o processo educacional e promove o conhecimento coletivo. Dessa forma, percebe-se que a colaboração tem um papel importante na construção do conhecimento.

A evolução do vínculo entre educação e tecnologia tem ampliado as possibilidades de proporcionar ambientes educacionais colaborativos. Comunidades virtuais de aprendizagem e redes sociais educacionais são exemplos de plataformas tecnológicas com inúmeros recursos que viabilizam a materialização do aprendizado em contextos heterogêneos e/ou geograficamente dispersos [Pimentel and Fuks 2011]. A Aprendizagem Colaborativa mediada por computador (CSCL) apresenta o grande desafio de investigar e explorar estas duas grandes áreas, o suporte computacional e a aprendizagem colaborativa, para dar suporte ao aprendizado [Jeong and Hmelo-Silver 2016].

Este capítulo tem por papel fundamental discutir os avanços e desafios da CSCL na era onde os recursos tecnológicos aplicados à aprendizagem têm sido exigidos para viabilizar as atividades acadêmicas no âmbito médio e superior. Faz parte deste capítulo conceitualizar a aprendizagem colaborativa com suporte computacional em tempos da Educação 4.0, discutir alguns métodos de ensino envolvidos, e principalmente discutir o framework Collab_Edu de suporte ao planejamento da colaboração antes da aplicação de qualquer iniciativa de aprendizagem colaborativa. Faz parte também das discussões desse capítulo propor reflexões a respeito da colaboração na educação em tempos de crise.

A organização deste capítulo é estruturada nas seguintes seções: (1) Colaboração na Educação 4.0, onde são discutidas as teorias de colaboração defendidas pela literatura; o framework Collab_Edu proposto com base na experiência prática dos autores e referências bibliográficas de suporte ao planejamento da colaboração. (2) Aprendizagem Colaborativa na Educação 4.0, discutindo a evolução histórica da aprendizagem colaborativa, as diferenças entre metodologia ativa e tradicional e os métodos de ensino. (3) Inovação Colaborativa na Educação 4.0 em tempos de Crise. (4) Considerações finais.

\subsection{Colaboração na Educação 4.0}

Ao longo dos últimos tempos, temos observado um grande avanço da educação na era 4.0. No entanto, apesar de boa parte das mudanças estarem ocorrendo em termos do papel do professor em sala de aula e dos recursos tecnológicos envolvidos, é notória a 
dificuldade de muitas escolas brasileiras se adaptarem tendo em vista a falta de capacitação, recursos privados e governamentais [Laval 2019].

A Educação na era digital é marcada pela mudança de comportamento dos indivíduos, e de suas interações na vida diária. A necessidade de lidar com problemas complexos levou ao surgimento de novas habilidades práticas, conhecimentos, atitudes e mudança comportamental. Essas mudanças são respostas à introdução de novas tecnologias e paradigmas na educação, de forma que os indivíduos estejam melhor preparados para lidar com as demandas da sociedade moderna.

Lin (2019) discute a aceitação do uso de tecnologias na educação e traz importantes reflexões sobre o tema. De acordo com [Fisk 2017, Hussin 2018], os alunos devem aprender não apenas as habilidades e conteúdos predeterminados, mas também a identificar fontes para aprender formas independentes na era da educação 4.0. Para difundir este paradigma de educação, algumas tendências são relacionadas [Garcia et al. 2020]:

1. uso de ferramentas de e-Learning (aprendizagem online), que oferecem oportunidades para aprendizado remoto e individualizado, que pode ser realizado a qualquer momento e em qualquer lugar;

2. A utilização de sala de aula invertida, onde o aprendizado interativo é realizado em sala de aula, enquanto o conteúdo teórico pode ser aprendido fora do horário da aula;

3. A liberdade aos alunos em escolher ferramentas ou técnicas de aprendizagem que preferem;

4. incentivo ao aprendizado prático, por meio de experiências de campo, como estágios, projetos de orientação, e projetos colaborativos;

5. A literacia de dados (Data Literacy) em que os alunos são expostos à interpretação dos dados, e incentivados a aplicar seus conhecimentos teóricos a números, e usar suas habilidades de raciocínio para fazer inferências baseadas na lógica e nas tendências de determinados conjuntos de dados;

6. A avaliação diferenciada por aluno, utilizando plataformas computacionais;

7. A consideração sobre a opinião dos alunos ao projetar e atualizar o currículo pedagógico; e,

8. A responsabilidade compartilhada de aprendizado entre professores e alunos.

Diante das tendências citadas, observa-se que a colaboração é um aspecto inerente a maioria. Ao pensar em ferramentas de e-learning, podemos discutir como essas mesmas ferramentas podem dar suporte a grupos de alunos em suas tarefas acadêmicas. Essas mesmas tarefas podem ser síncronas ou assíncronas, sendo necessário um planejamento claro da colaboração necessária para o desenvolvimento da tarefa.

$\mathrm{Na}$ era da Educação 4.0, observamos, que a avaliação colaborativa de alunos a partir de plataformas computacionais é factível, onde os próprios pares acompanhados por um tutor poderiam se envolver nesta atividade. As teorias da colaboração já têm sido amplamente aplicadas na educação, no entanto, pouco preparo tem sido dedicado a este assunto. O que se observa na prática é a junção de alunos em um grupo, sem considerar aspectos como: características pessoais dos alunos, nível já absorvido do conteúdo, local 
para o desenvolvimento da tarefa e recursos tecnológicos necessários. É importante destacar que o indivíduo assimila informações de maneira diferente diante das múltiplas mídias disponíveis e, para isso, o especialista (em nosso caso professor, instrutor ou tutor) precisa repensar as maneiras de transmitir o conhecimento. Nesta seção, a relação das tendências da Educação 4.0 é discutida à luz da colaboração. Nas subseções a seguir serão apresentadas as teorias e modelos de colaboração e também um framework de suporte ao planejamento da colaboração na Educação 4.0.

\subsubsection{Teorias e modelos de colaboração}

De acordo com Fuks et al. (2011), as teorias e modelos, de são de fundamental interesse para apoiar a seleção e projeto de sistemas apoiados no trabalho em grupo. Através dessas teorias e modelos é possível compreender como as pessoas colaboram e como se relacionam com o uso da tecnologia. Ao direcionar nossa atenção para a área de aprendizagem colaborativa, as teorias e modelos de colaboração atuam como efetivos na definição de ferramental tecnológico para apoio da aprendizagem colaborativa, além de dar suporte ao entendimento das interações sociais e de aprendizagem necessárias. Nesta subseção serão apresentadas algumas teorias e modelos da colaboração como Teoria de Jogos, Teoria da Evolução da Colaboração, Teoria da Atividade, Modelo 3C de colaboração.

$\mathrm{Na}$ Teoria dos Jogos, a relevância está nos cenários de tomadas decisões estratégicas onde o resultado de cada participante depende da decisão dos demais envolvidos na sessão colaborativa. Um exemplo clássico é a fuga de congestionamentos de trânsito em véspera de feriado. Considere que poucas pessoas terão disposição para levantar-se mais cedo da cama e dirigir-se a estrada rumo ao seu destino para o feriado. Neste caso, a decisão indicada para fugir do trânsito seria acordar mais cedo para ter o caminho livre. Contudo, se estivermos enganados e a maioria pensar como nós, o caminho estará congestionado para nós e livre para os pouco que dormiram até mais tarde.

A Teoria da Evolução da Colaboração defende como a colaboração emerge e se mantém em um cenário competitivo. Essa teoria, também conhecida como "toma lá dá cá" ("tit for tat"), segue três regras básicas: (i) Contribua. Nunca seja o primeiro a trair; (ii) Se for traído, retalie; (iii) Esteja preparado para perdoar a traição após uma retaliação. A Teoria da Atividade apresenta como os seres humanos realizam atividades em situações cotidianas, individualmente e em sociedade. Nessa teoria, a atividade apoia a compreensão das ações de uma pessoa ou um grupo. Essas realizam ações sobre um objeto a fim de alcançar um objetivo. Neste caso, um objeto pode ser concreto como um documento, ou abstrato como uma ideia ou decisão a ser tomada.

Os três fundamentos que viabilizam o trabalho em grupo (colaboração) são: comunicação, coordenação e cooperação. Esta classificação veio a ser conhecida como o Modelo 3C de colaboração. Mais tarde, o modelo foi estendido para incluir o papel da percepção (awareness) do indivíduo nas relações entre os 3C's (Figura 1.1). 


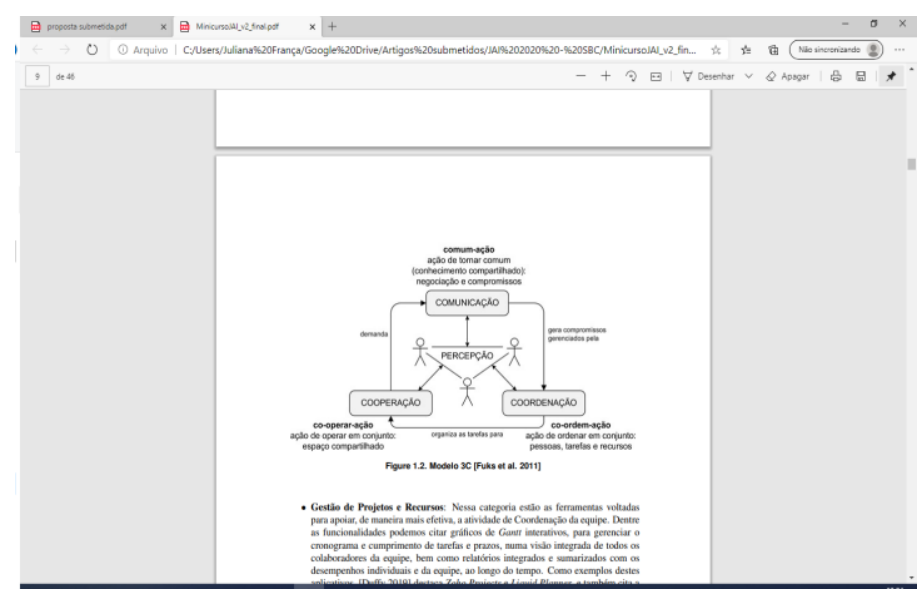

Figura 1.1. Modelo 3C [Fuks et al. 2011]

A Comunicação pode tomar várias formas: troca de mensagens, argumentação e negociação entre pessoas; a Coordenação inclui o gerenciamento de pessoas, atividades e recursos e a Cooperação é a ação conjunta em espaço compartilhado para a produção de objetos e informações. Este espaço pode ser um espaço virtual, pasta compartilhada, mesa digital ou qualquer outro tipo de espaço onde o trabalho seja realizado por um grupo de pessoas. Através da Percepção, o indivíduo se mantém informado sobre o andamento do trabalho do grupo: como está o andamento global, sobre o que as outras pessoas estão conversando, no que elas estão trabalhando, qual o objetivo de cada um e seu papel no contexto de trabalho e que informações são necessárias para seu trabalho.

O Modelo 3C exerce influência direta na concepção e desenvolvimento de sistemas de groupware (ferramentas tecnológicas tendo como fundamento os aspectos da colaboração). A literatura discutiu e tem discutido a engenharia de groupware fundamentada no Modelo 3C. As ferramentas de groupware tem se mostrado fortemente inseridas na sociedade. Muito desta constatação se dá por sua raiz nos conceitos explorados no modelo 3C. Em sociedade, observa-se uma necessidade por relações interpessoais, pelo estabelecimento de protocolos, de compromissos e por tomada de decisões em conjunto a fim de que o trabalho possa ser realizado e objetivos possam ser alcançados. Com base nisso, temos observado uma demanda por groupwares para a condução de trabalhos, aulas e interações sociais. Em momentos em que a presença física se torna um impedimento, estratégias tecnológicas que mantenham o contato virtual e fomentem ações colaborativas têm sido empregadas.

Diferentes são as funcionalidades exigidas a fim de que uma ferramenta tecnológica possa ser colaborativa. O Modelo 3C tem, portanto, o papel de orientar sobre quais funções devem ser previstas nessas ferramentas, classificadas de acordo com seus prismas: comunicação, cooperação e coordenação. Ferramentas de troca de mensagens instantâneas estão cada vez mais aprimoradas, permitindo o envio de textos, áudio, imagens, vídeos, sem contar a troca de emoções através do uso de emojis. Exemplos clássicos são Whatsapp, Telegram, Zoom, Hangout. Essas ferramentas apresentam claramente estratégias de comunicação entre indivíduos onde ações de negociação e afirmação de compromissos são observadas a fim de que as partes se entendam. Há também ferramentas de comunicação onde a interação não precisa acontecer em tempo real como ocorre nos Emails. 
Dessa forma, vemos que a comunicação pode ocorrer através de linguagem verbal, textual, corporal ou de sinais; e também de acordo com o tipo de comunicação: síncrona ou assíncrona. A comunicação onde o emissor e receptor enviam e respondem mensagens em um intervalo de tempo pequeno, quase imediato é do tipo síncrona; enquanto na assíncrona, o emissor envia uma mensagem e não espera resposta rapidamente, i.e., a mensagem fica armazenada até que o receptor leia e responda.

O papel da coordenação nas ferramentas de groupware está relacionado à organização do grupo para evitar que esforços de comunicação e de cooperação sejam perdidos e para que as tarefas sejam realizadas na ordem correta, no tempo correto e cumprindo as restrições e objetivos. Exemplos de ferramentas de groupware que atuam frente à coordenação de tarefas são: Workflow, Discord.

Apesar de vitais, a comunicação e a coordenação não são suficientes. É necessário um espaço para criar entendimento compartilhado. Cooperação é a operação conjunta dos membros do grupo no espaço compartilhado visando a realização das tarefas gerenciadas pela coordenação. Indivíduos cooperam produzindo, manipulando e organizando informações, construindo e refinando objetos de cooperação, como textos, planilhas e gráficos. Exemplos de ferramentas atuais que atuam sob os objetivos da cooperação são: Dropbox, GoogleDrive, OverLeaf.

\subsubsection{Collab_Edu: Planejamento da Colaboração em Educação}

Estudos apontam que a aplicação de estratégias da aprendizagem colaborativa tem apresentado melhores resultados quanto ao engajamento dos alunos, motivação pela aprendizagem e resultados acadêmicos; quando há planejamento da colaboração necessária para o cumprimento das tarefas [Tardelli et al. 2019, Ferreira et al. 2020, Reis e Isotani 2019]. Diante disto, o framework Collab_Edu propõe uma estratégia de planejamento da colaboração com finalidades educacionais. O papel do framework Collab_Edu é orientar professores, gestores e tutores na organização das tarefas em grupo, permitindo um trabalho direcionado aos alunos quanto aos aspectos de colaboração esperados. Esse Framework impactará também os alunos, permitindo que eles conheçam como a colaboração em grupo deve acontecer a fim de que os resultados da tarefa sejam mais promissores.

Conforme pode ser visto na Figura 1.2, o framework é estruturado em quatro módulos: 'Definição da atividade', 'Dinâmica da atividade', 'Ferramentas necessárias' e 'Formação de grupo'. Cada um desses módulos é organizado com base nos pilares do Modelo 3C: comunicação, cooperação, coordenação e percepção [Fuks et al. 2011]. A Figura 1.3 faz um mapeamento objetivo dos conceitos inerentes a cada um dos pilares do Modelo 3C, frente aos módulos do Collab_Edu. 


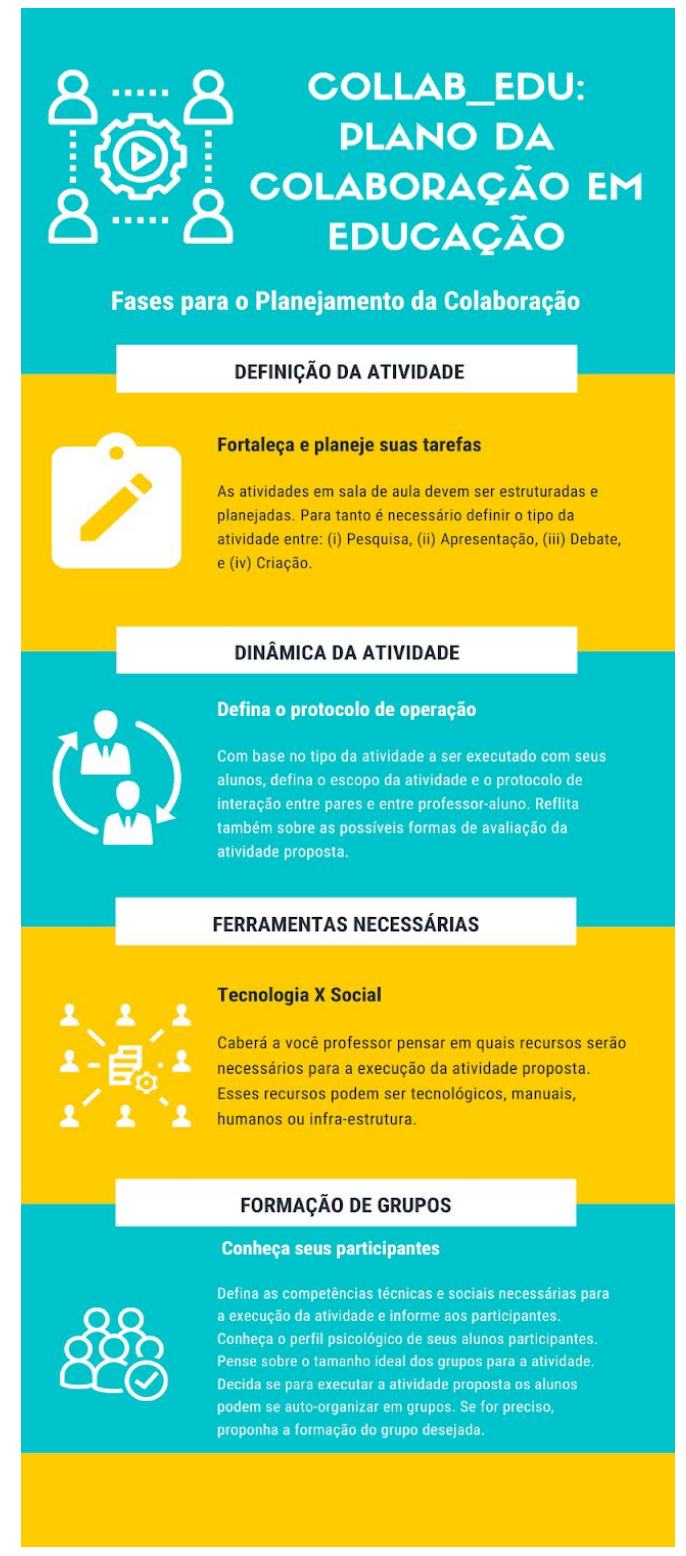

Figura 1.2. Framework de planejamento da colaboração em educação

O Módulo Definição da Atividade visa orientar professores e alunos quanto ao tipo de atividade a ser desempenhada. Esse módulo apresenta aos professores quatro potenciais tipos de tarefa (Pesquisa, Apresentação, Debate e Criação). Caberá ao professor escolher um dos tipos, ou mesmo, uma integração de tipos diferentes, a fim de que os alunos pratiquem os novos saberes desenvolvidos. Caberá ao aluno se preparar para a execução de tarefas com o tipo definido. Neste módulo será necessário um entendimento pleno do tipo de atividade e dos participantes da aula/atividade educacional. É importante investigar também como esta atividade se enquadra no planejamento da aula desenvolvido pelo professor, e se há um espaço compartilhado disponível para os alunos participarem da atividade. 


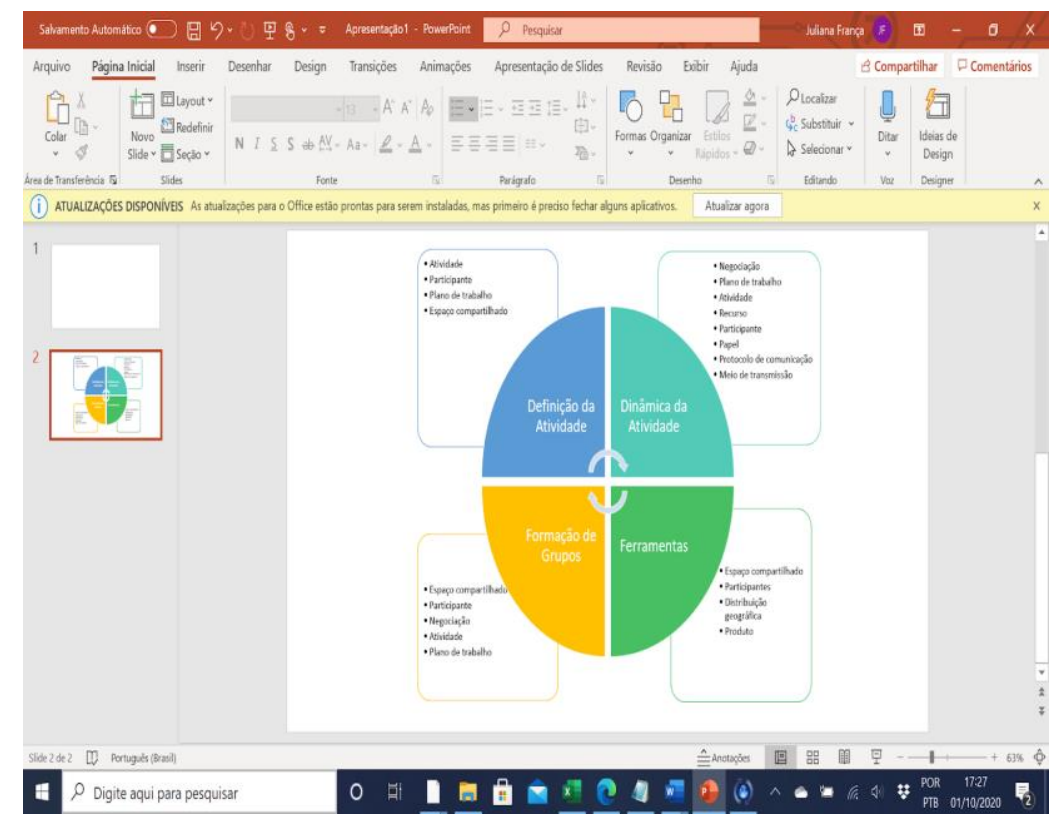

Figura 1.3. Mapeamento dos conceitos da ontologia de colaboração [Vivacqua and Garcia 2011] sobre os módulos do framework Collab_Edu

No módulo Dinâmica da Atividade, os professores deverão informar ou negociar qual protocolo de interação é esperado que seja executado pelo grupo entre professoraluno, aluno-aluno, professor-professor. $\mathrm{O}$ grupo deverá buscar pelo senso comum ou haverá um representante com maior poder de decisão no grupo? É esperado também que os professores informem os pré-requisitos da atividade (competências técnicas e sociais exigidas, tempo disponível, espaço físico ou virtual disponíveis, infra-estrutura necessárias). O professor deverá orientar seus alunos quanto ao tipo de avaliação, informando os produtos que deverão ser produzidos e entregues, além dos aspectos subjetivos que estarão em avaliação.

O módulo Ferramentas Necessárias visa orientar tanto professor, aluno, tutores e gestores educacionais sobre as ferramentas necessárias para as práticas de ensino. Essas ferramentas podem ser tecnológicas ou não. No entanto, todos os papéis envolvidos precisam conhecer as potencialidades das ferramentas a fim de que a experiência educacional seja plena e sem interferência externa ao aprendizado. Neste módulo, os papéis envolvidos deverão se organizar, tendo como premissa as: discussões que levem a resultados sobre o espaço compartilhado necessário para uso da ferramenta e condução da atividade; conhecer os participantes da atividade e qual a relação deles com as ferramentas escolhidas; negociar com os participantes sua capacitação sobre as ferramentas que serão usadas nas atividades educacionais; verificar se a atividade educacional, quando executada na ferramenta proposta, é capaz de gerar os produtos esperados; entender qual a distribuição geográfica dos participantes da atividade e, portanto, quais requisitos a ferramenta usada na atividade deve atender.

Na Formação de Grupos, o planejamento da colaboração é trabalhado tendo como objeto de investigação as características dos alunos na atividade educacional. Neste módulo, o planejamento da colaboração destaca a necessidade em conhecer o perfil psicológico dos alunos participantes e como a junção de perfis similares ou diferentes podem impactar a execução da atividade em grupo. Para planejar a formação de grupos, a atividade proposta deve ser bem entendida para que o professor consiga definir o 
tamanho dos grupos. Se existe a necessidade por tarefas em grupo com alto grau de discussão orientada, a preferência deve ser por grupos menores (até 5 participantes) e auto organizados. Caso a necessidade seja por alto grau de prospecção, grupos maiores (até 8 participantes) são indicados para concentrar no grupo diferentes pontos de vista e perfis sociais.

É importante destacar que o Collab-Edu propõe uma orientação para apoiar o planejamento da colaboração em atividades educacionais. Este framework não apresenta aspectos assertivos, mas sim destaca ações importantes que precisam ser pensadas e definidas antes da execução da atividade educacional colaborativa. Na próxima seção será discutida a aprendizagem colaborativa com suporte educacional na era da educação 4.0.

\subsection{Aprendizagem Colaborativa com Suporte Computacional na Educação 4.0}

A aprendizagem colaborativa é um ramo das ciências da aprendizagem que estuda como as pessoas podem aprender em grupo. A aprendizagem colaborativa apresenta uma visão pedagógica baseada em teoria e pesquisa de como o CSCL poderia ser dado o desenvolvimento de suportes computacionais inovadores e novas formas de conceituar conhecimento (epistemologia), pensamento (cognição) e aprendizagem (colaborativa).

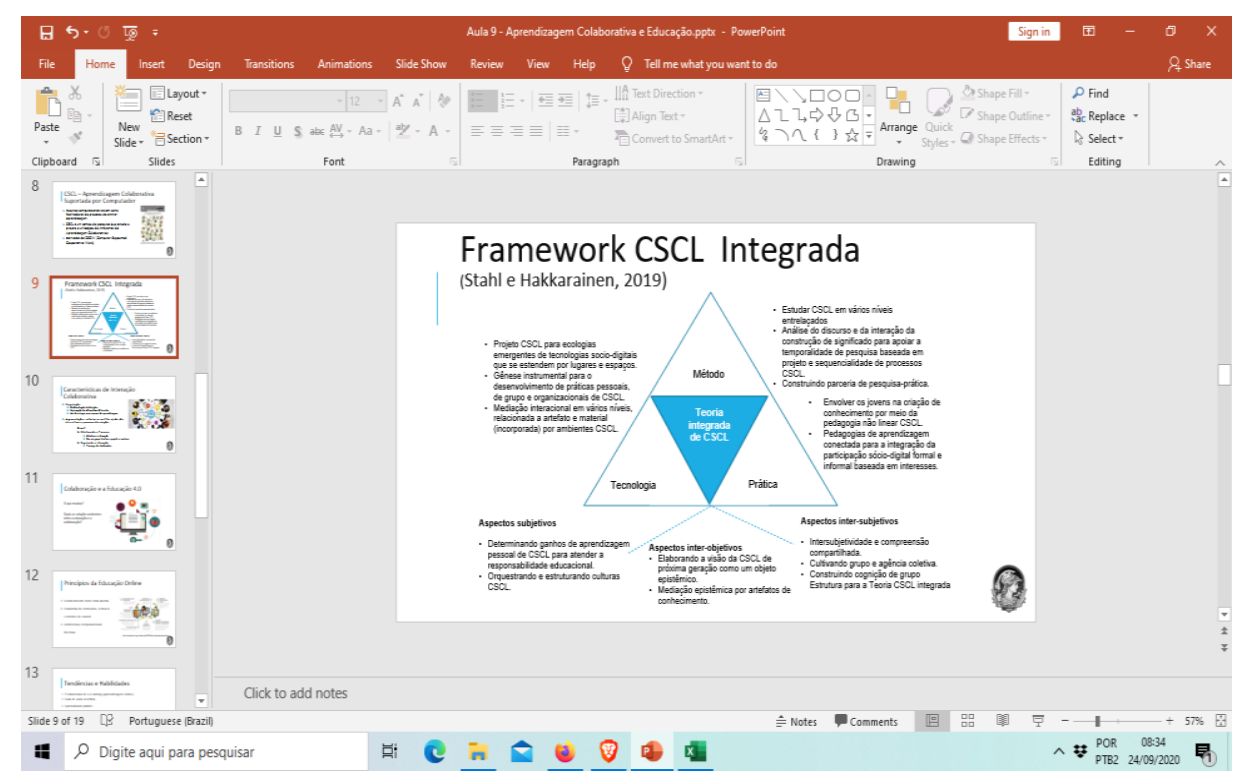

Figura 1.4. Framework CSCL [Adaptado de Stahl and Hakkarainen 2020]

A Figura 1.4 apresenta uma análise das inter-relações e modelagem mútuas entre as tecnologias, práticas e métodos para CSCL caracterizados como:

- Tecnologia: Com o surgimento do campo CSCL foi associado ao desenvolvimento de tecnologias de informação e comunicação ou sistemas de groupware que possibilitaram a interação e colaboração síncronas e assíncronas entre os alunos. Estes desenvolvimentos inspiraram ambientes e teorias para a aprendizagem colaborativa, que continuaram sendo mediados e desenvolvidos por tecnologias sócio digitais. No entanto, o uso de aplicativos de mídia social com foco tradicional da CSCL, vem sendo usados com aplicativos especializados para colaboração. A mídia social desenvolvida comercialmente como Facebook ou Twitter são predominantemente projetadas para a troca de opiniões pessoais 
(resultando em muitas notícias e fake news), em vez de apoiar processos de construção de conhecimento.

- Método: Para aplicação de CSCL são necessários um conjunto de métodos, processos e práticas. Eles contribuem para o redesenho das tecnologias e modelos pedagógicos a aplicação. As análises das aplicações de CSCL motivaram teorias de cognição que são distribuídas de forma temporal e social. O campo de pesquisa da CSCL desenvolveu métodos específicos e práticas investigativas para estudar a aprendizagem colaborativa em vários níveis: desde o indivíduo e pequenos grupos até a sala de aula / comunidade / unidades culturais / sociais de análise.

- Prática: Os impactos das tecnologias CSCL são mediados tanto por práticas educacionais existentes, quanto pelo uso difundido dessas tecnologias na aprendizagem. O uso educacional das tecnologias CSCL é um esforço sistêmico ancorado nas práticas sociais de alunos, professores e instituições educacionais. Os pesquisadores da área de CSCL têm buscado desenvolver estruturas pedagógicas e diretrizes para apoiar a inovação da CSCL juntamente com o desenvolvimento de teorias para a compreensão das práticas e sua dinâmica transformadora. $\mathrm{O}$ uso e implementação do CSCL pode melhorar a qualidade da aprendizagem, democratizar o conhecimento e promover a igualdade do aprendizado através de experimentos de modelos iterativos e colaborativos no contexto educacional.

Entende-se que a teoria de CSCL é uma visão pedagógica baseada em teoria e pesquisa de como a aprendizagem colaborativa poderia ser dado o desenvolvimento de suportes computacionais inovadores e novas formas de conceituar conhecimento (epistemologia), pensamento (cognição) e aprendizagem (colaborativa). Portanto, CSCL não é simplesmente o estudo do uso de tecnologias existentes em ambientes educacionais convencionais, conforme analisado por métodos e teorias tradicionais. A seguir, será discutida a evolução histórica da aprendizagem colaborativa com suporte computacional.

\subsubsection{Evolução histórica da Aprendizagem Colaborativa com Suporte Computacional}

De acordo com Stahl et al. (2006), CSCL teve sua ascensão em 1996, com o principal objetivo de reagir aos softwares da época que visavam estimular o ensino individualista e com poucas interações em grupo. Isso foi possível dada a estrutura web já disponível nesta época.

No entanto, durante o desenvolvimento da CSCL, os problemas de design, disseminação, e o aproveitamento das vantagens trazidas pelos novos softwares educacionais tornaram-se cada vez mais aparente. Diante disso, ficou clara a necessidade de transformação do conceito de aprendizagem no ensino e em como ser aluno e professor. Com as discussões e novas propostas de métodos de ensino via os paradigmas da CSCL, o professor deixa de assumir o protagonismo absoluto em suas aulas e o aluno passa a exercer o papel de co-criação e co-desenvolvimento dos novos saberes discutidos.

Ao traçar um paralelo com os dias atuais, percebe-se uma crescente evolução dos paradigmas de CSCL aplicados ao ensino. Hoje, as discussões vão além se a aula colaborativa será a distância, presencial ou online, mas sim se a estrutura pedagógica e a infra-estrutura previstas são suficientes a fim de envolver o aluno no processo ensinoaprendizagem. Para aprofundar essa discussão, apresentamos a seguir as características e diferenças entre metodologia ativa e tradicional. 


\subsubsection{Diferenças entre metodologia ativa e tradicional}

Para Bacich e Moran (2018), o uso de "metodologias ativas são estratégias de ensino centradas na participação efetiva dos estudantes na construção do processo de aprendizagem, de forma flexível e interligada". A metodologia ativa é qualquer abordagem onde todos os alunos participam ativamente do processo de aprendizagem.

$\mathrm{O}$ aprendizado ativo pode assumir muitas formas e ser executado em qualquer disciplina. Comumente, os alunos se engajam em atividades pequenas ou grandes centradas em escrever, falar, resolver problemas ou refletir. A metodologia ativa está em contraste com os métodos tradicionais de ensino, pela mudança de papel do aluno.

$\mathrm{Na}$ abordagem tradicional, os alunos são receptores passivos de conhecimento de um especialista. Na ativa, os alunos participam ativamente da construção do conhecimento com o apoio de um especialista. A mudança fundamental está no papel que o professor assume, passando de protagonista para coadjuvante no processo de aprendizado de seus alunos. De acordo com [Costa et al. 2020], as principais vantagens das metodologias ativas (centrada no aluno) são:

- Estimular as diferentes formas dos alunos aprenderem: considerando diferentes objetos de aprendizagem.

- Estimular as competências da era atual: O enfoque maior será explorar o comportamento proativo de alunos, competências colaborativas, abertura para interação com objetos tecnológicos em atividades de aprendizagem.

- Deixar as aulas mais dinâmicas: Explorar a atuação do aluno como também provedor de novos conhecimentos e inserção de recursos tecnológicos na aprendizagem que já fazem parte do dia a dia dos alunos como: redes sociais, histórias e games.

Enquanto as principais desvantagens das metodologias ativas são destacadas por:

- Maior dificuldade na garantia de um aprendizado comum a todos: É preciso direcionar o ensino para a necessidade individual de cada aluno. Dessa forma, há uma mudança de paradigma de ensino onde o aluno passa ser o protagonista e quem demandará suas necessidades individuais para o processo de ensinoaprendizagem.

- Difícil aceitação dos alunos no começo (já que exige mais esforço): é preciso propor soluções para as dificuldades de introduzir mudança cultural em um sistema de ensino com práticas muito arraigadas no ensino passivo.

Algumas metodologias ativas ganharam muita notoriedade nos últimos anos, tanto no meio científico, quanto em sala de aula. Vários pesquisadores buscaram comprovar a efetividade dessas metodologias, enquanto elas eram praticadas por milhões de professores brasileiros em sala de aula. Dentre as principais metodologias ativas podemos citar: Ensino Híbrido, Aprendizagem baseada em problemas, Aprendizagem baseada em projetos, Rotinas de pensamento (Thinking Routines), Aprendizagem baseada em equipes. Na próxima subseção serão discutidos em detalhes as metodologias destacadas. 


\subsubsection{Métodos de Ensino}

Nesta seção apresentaremos alguns métodos de ensino difundidos na literatura e sua interface com a aprendizagem colaborativa. Esses métodos serão: Sala de Aula Invertida, Aprendizagem baseada em projetos, Rotina de pensamentos, Aprendizagem baseada em equipes, Aprendizagem baseada em problemas. Para a prática de cada método, é recomendado planejar as estratégias de colaboração e, portanto, o Framework Collab_Edu é indicado para ser aplicado antes da execução dos métodos de ensino com fundamentos de colaboração.

\section{- Ensino Híbrido - Sala de aula invertida (Flipped Classroom)}

O Ensino Híbrido é um modelo de educação formal que se caracteriza por mesclar dois modos de ensino: Online e Offline. No online, o aluno possui controle sobre algum elemento do seu estudo na escola ou fora dela, como o tempo, forma, ritmo ou local. Já o offline deve ser realizado na escola, e pode ter vários momentos diferentes [Stöhr et al. 2020].

Nesse sentido, a ideia é a parte online e offline se conectarem e complementarem, proporcionando diferentes formas de ensinar e aprender. Existem vários modelos de ensino híbrido: os sustentados e os disruptivos. Os sustentados são conhecidos como: "rotação por estações", "laboratório rotacional", "rotação individual" e "sala de aula invertida". Já os disruptivos são: "modelo flex", "modelo à la carte", "modelo virtual enriquecido".

A aula invertida tem sido vista de forma reducionista como assistir vídeos antes e realizar atividades presenciais em um segundo momento. Essa é uma das formas de inversão. $\mathrm{O}$ aluno pode partir de pesquisas, projetos e produções para iniciar-se em um assunto e, em seguida, aprofundar seu conhecimento e competências com atividades supervisionadas. Dentro de um cenário online o modelo pode ser utilizado para aumentar a interação do aluno com seus colegas e com o professor.

O modelo de sala de aula invertida pode ter um alcance ainda maior quando é combinada com algumas dimensões da personalidade do aluno e sua individualidade, como autonomia e a flexibilização. Parte do processo de aprendizado pode ser iniciado antes do encontro coletivo da sala de aula e pós sala de aula.

A atividade em sala de aula invertida é realizada para estimular a investigação e/ou design e permitir envolver os alunos em cada fase das atividades com o objetivo de ampliar o conhecimento, a aquisição de habilidades e o processo de resolução de problemas. Neste método os alunos aprendem novos fundamentos conforme necessário. Estudos como os de [Reidsema el al. 2017, Keengwe 2014, Stohr et al. 2020, Schneiders 2018], propõem uma análise do local onde será conduzida a atividade educacional, para a partir disso realizar uma análise das ferramentas tecnológicas a serem empregadas.

A estratégia ativa - aula invertida e um modelo híbrido - otimiza o tempo da aprendizagem e do professor. O conhecimento básico ficando a cargo do aluno e as fases seguintes têm a interferência do professor e a interação dos grupos na sala de aula presencial ou virtual. Bergmann e Sams (2016) foram os pioneiros de algumas técnicas da aula invertida utilizando o vídeo como material para estudo prévio, com a vantagem de que cada aluno fique livre para assistir em seu ritmo o material disponibilizado pelo professor. 
A metodologia para a sala de aula invertida apresenta atividades individuais e em equipe, estudos de caso, leitura, dinâmicas em sala de aula, apresentações, entre outras atividades que acabam contemplando todos os estilos de aprendizagem, tornando a aula mais dinâmica e interativa [Trevelin et al. 2013, Awidi and Paynter 2019]. Estes estudos identificaram que o uso das metodologias de aula invertida pode ser observado no desempenho dos alunos apresentando uma melhoria quantitativa e qualitativa no desempenho. Além disso, a partir do planejamento da colaboração nos grupos de sala de aula e aplicação do método também mostrou eficiência de forma positiva em relação aos professores.

\section{- Rotinas de pensamento (Thinking Routines)}

As rotinas de pensamento (Thinking Routines) são definidas por padrões simples de pensamento que podem ser usados no aprendizado de diferentes áreas de forma repetida. Este método aplicado em sala de aula oferece aos alunos estruturas com uso de ferramentas promovendo ambientes de aprendizado interativo. As Rotinas de Pensamento também podem ser pensadas como um padrão de comportamento e uma manifestação do modo de operação de um grupo [Sepulveda and Venegas-Muggli 2019].

Para os autores [Wolberg and Goff 2012, Pinedo et al. 2018], a experiência de construção de significados dentro das Rotinas de Pensamento envolvem uma variedade de contextos e experiências sociais. Além disso, os estudos tratam da aquisição da linguagem que afetam diretamente o desenvolvimento cognitivo fornecendo ao aluno uma linguagem comum de pensamento, através de ferramentas apropriadas.

Os estudos sobre este método, enfatizam o papel fundamental da interação social promovendo a compreensão. O pensar engloba uma gama de habilidades cognitivas que incluem fazer comparações, raciocinar, analisar, deduzir e refletir, habilidades que são relevantes independentemente do ambiente de aprendizagem. Um aluno exposto a diferentes tipos de pensar, pode tornar-se mais consciente de maneiras significativas para interagir com diferentes artefatos. Estes pensamentos e estratégias podem fortalecer o planejamento de tarefas de colaboração e, com isso potencializar o método e o desempenho do aluno.

A partir do uso de modelos colaborativos e uma estratégia de aprendizagem voltada para Rotinas de pensamento, espera-se fortalecer e apoiar a aprendizagem e pensamento do aluno. A oportunidade de usar estratégias e desenvolver habilidades dentro de vários contextos, nutrem o processo de aprendizagem e torna todo a experiência mais pessoal e relevante para os alunos e educadores. O propósito de rotinas de pensamento de forma simples, explícitas, de fácil aprendizagem é oferecer aos educadores possibilidades de criar experiências de aprendizagem inovadoras.

\section{- Aprendizagem baseada em equipes (Team-Based Learning)}

A aprendizagem baseada em equipes é uma estratégia de ensino projetada para apoiar o desenvolvimento de equipes de aprendizado de alto desempenho e oferecer oportunidades para essas equipes se engajarem em tarefas significativas de aprendizado [Fink 2004]. Originalmente desenvolvido para escolas de administração, a aprendizagem baseada em equipes é estruturada em quatro princípios: (i) Os grupos devem ser adequadamente formados e gerenciados; (ii) os alunos devem ser responsabilizados por seus trabalhos em grupo; (iii) as tarefas de grupo devem promover tanto o aprendizado quanto $\mathrm{o}$ 
desenvolvimento de equipes; e (iv) os alunos devem ter feedback de desempenho frequente e oportuno [Johnson 2009].

Para Michaelsen et al (2008) estudos de TBL (Team-Based Learning) são voltados para criar e implementar atribuições de grupos. Os autores destacam os elementos chave para conduzir o trabalho em grupos de maneira eficaz: (i) as atribuições devem sempre ser projetadas em torno de um problema que seja significativo para os alunos; (ii) todos os alunos da turma devem estar trabalhando no mesmo problema; (iii) os alunos devem ser solicitados a fazer uma escolha específica com relação à solução do problema; e (iv) os grupos devem relatar simultaneamente suas escolhas (Figura 1.5). Além disso, os procedimentos se aplicam a todos os três estágios nos quais os alunos preparam suas atividades individuais antes das discussões em grupo, discussões com grupos e discussão com toda a classe entre os grupos.

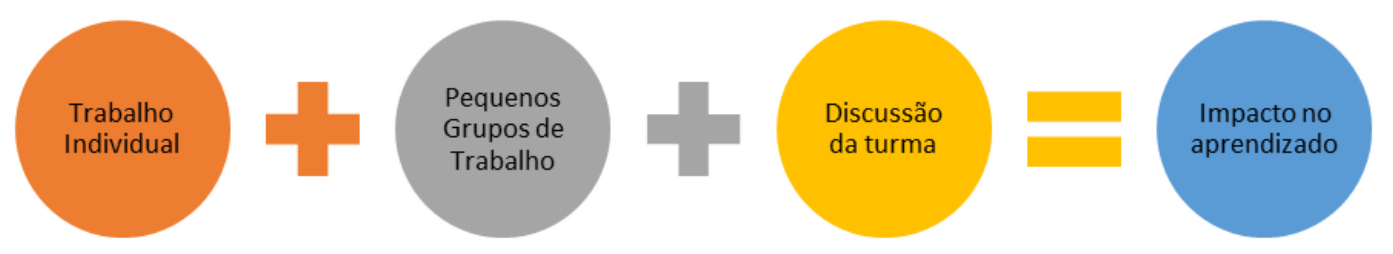

Figura 1.5. Framework de Criação de Grupo de Trabalho Efetivo (Adaptado de Michaelsen, 2008)

Os autores também apresentam os principais fatores para obter o máximo impacto positivo na aprendizagem, considerando a organização proposta na Figura 1.5:

- Significativo - indivíduos e grupos devem trabalhar em um problema, caso ou questões que demonstrem a utilidade do conceito;

- Problema de semântica - indivíduos e grupos devem trabalhar no mesmo problema, caso ou questão;

- Escolha específica - indivíduos e grupos devem ser obrigados a usar os conceitos do curso para fazer uma escolha específica;

- Relatar simultaneamente - se possível, indivíduos e grupos devem relatar suas escolhas simultaneamente.

O estudo demonstra que a melhor forma de atingir o objetivo da atividade é exigir que os alunos façam uma escolha específica. É importante que os membros recebam informações e produza uma decisão simples. Na sala de aula, a melhor maneira de promover a discussão relacionada ao conteúdo é usar tarefas que requeiram grupos, que trabalhem de forma colaborativa para usar os conceitos e tomar decisões sobre questões apresentadas.

O uso de Aprendizagem Baseada em Equipe (TBL) na educação cresceu exponencialmente e não se restringe a área de educação. TBL tem sido aplicado também na área de saúde. No entanto, até o momento os estudos se basearam em medidas tradicionais de sucesso acadêmico, como pontuações em testes e avaliações do curso [Reimschisel 2017]. Estudos de TBL futuros devem controlar fatores potencialmente confusos, como tempo na tarefa, desenvolvimento profissional fornecido aos facilitadores 
antes de implementar TBL, e o efeito de novas técnicas de ensino no envolvimento do professor e aluno.

\section{- Aprendizagem baseada em problemas (Problem-Based Learning)}

A aprendizagem baseada em problemas (Problem-Based Learning), é a construção do conhecimento a partir da discussão em grupo de um problema [Boud and Feletti 1998, Savin-Baden and Major 2004]. Nela, o aluno estuda individualmente sobre determinado assunto antes da aula, e registra todas as suas dúvidas ou dificuldades. Durante a aula, acontecem discussões em grupo sobre os problemas apresentados e diferentes pontos de vista são considerados sobre a questão. Esta dinâmica tem por papel enriquecer os envolvidos, desenvolvendo neles novas competências e permitindo que novos horizontes sobre o problema seja atingido. Desta forma, a participação de cada aluno no grupo de discussão é essencial, incentivando o trabalho em equipe e a comunicação.

O interesse sobre Aprendizagem Baseada em Problemas (PBL) tem crescido nos ambientes educacionais. No entanto, a abordagem apresenta desafios, principalmente no que tange as formas de aprendizagem orientada a ação. A PBL é uma abordagem na qual é afetado pelo ambiente estrutural e pedagógico em que é inserida. Ela pode receber estímulos tanto na própria disciplina, dos professores ou institucional. Embora reconheçamos que a aprendizagem baseada em problemas necessite de mudanças, existem aspectos delineados que possibilitam a organização de construtos teóricos apoiando uma análise mais profunda no ciclo da aprendizagem baseada em problema.

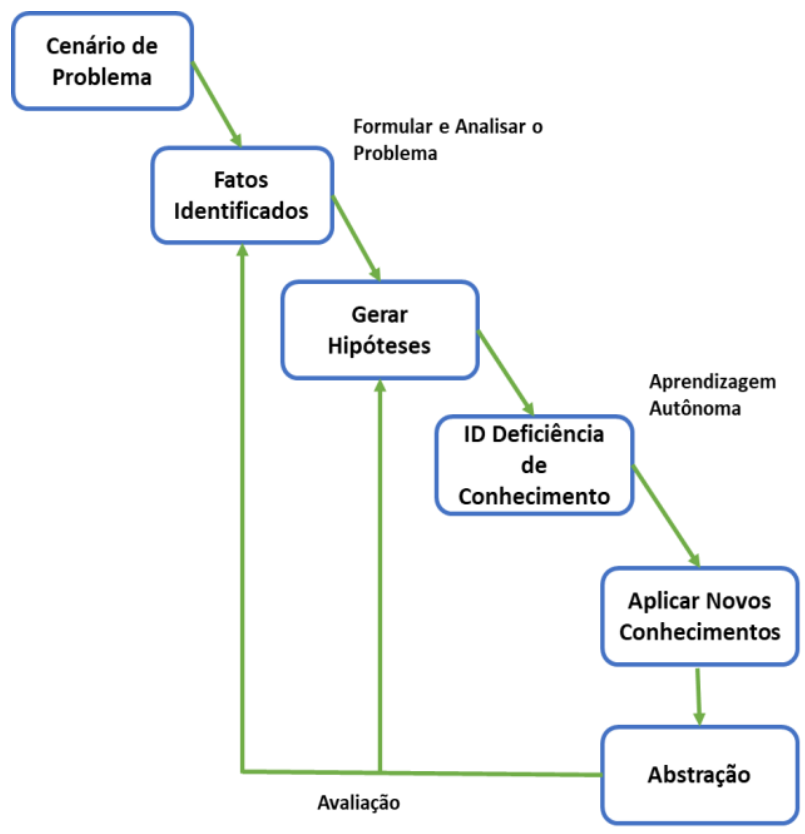

Figura 1.6. Ciclo da aprendizagem baseada em problema [Adaptado de Hmelo-Silver 2004]

O ciclo de aprendizagem apresentado na Figura 1.6 está baseado na solução de problemas e engloba 6 fases: (i) Cenário de problema: os alunos discutem a natureza do problema; (ii) Fatos identificados: levantamento de elementos relacionados ao problema; (iii) Gerar hipóteses: os alunos levantam as hipóteses encontradas no cenário; (iv) ID 
Deficiência de Conhecimento: os alunos buscam habilidades e conhecimentos não existentes no grupo; (v) Aplicar Novos Conhecimentos: as necessidades de conhecimentos novos são compartilhadas e aplicadas nos grupos; e (vi) Abstração: os alunos são convidados a abstrair suas ideias e buscar soluções.

A aprendizagem baseada em problemas permite ao aluno rever fatos identificados anteriormente, podendo gerar novas hipóteses sobre eles. Este ciclo também permite que o aluno reforce o aprendizado buscando de forma autônoma expandir o conhecimento.

\subsection{Inovação colaborativa na Educação em tempos de Crise}

O Educação 4.0 faz menção ao conceito e uso de Internet inteligente que afirma que os conteúdos destinados aos internautas serão cada vez mais personalizados e interativos. Diante desse cenário, temos como principal característica o fato de as tecnologias estarem cada vez mais no nosso cotidiano, e também dentro da sala de aula, promovendo e estimulando a troca de conhecimento.

O foco, porém, vai deixando de ser somente os recursos tecnológicos e passa a ser o como utilizar as ferramentas digitais e como elas podem proporcionar interação, ludicidade e o fazer coletivo. Um grande desafio da educação nos tempos atuais está em repensar formas de aprender no contexto colaborativo e virtual. Dunwill (2016) discute mudanças que devem ser estruturadas e planejadas para um futuro próximo. Entre elas está a adoção de diferentes modelos de tarefas, capazes de acomodar estilos distintos de aprendizagem como a CSCL. Os ambientes de aprendizado digital e colaborativo têm gerado mudanças em como as instituições constroem seus ecossistemas de aprendizagem, tanto para alunos quanto para os professores.

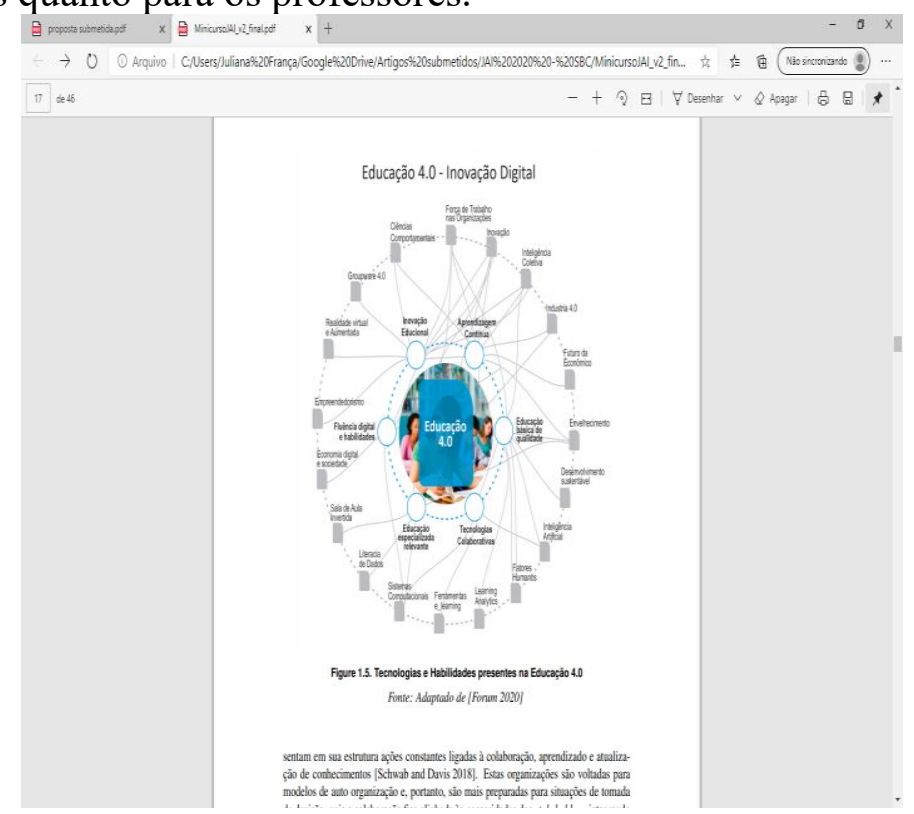

Figura 1.7. Educação 4.0 - Estratégias de inovação [Garcia et al. 2020]

A tecnologia traz, a cada dia, uma infinidade de novas oportunidades e um enorme crescimento. Este novo cenário exige diferentes perfis que promovam o trabalho em equipe, promovendo a resiliência, respeito, a diversidade, a criatividade, facilidade para tomada de decisão e liderança, que passam a fazer parte da lista de requisitos exigidos nas equipes. É preciso preparar os alunos para atuarem nesse novo contexto, principalmente em tempos de COVID19 (provocada pelo novo coronavírus (SARS-CoV-2)). Tendo o 
ambiente escolar que ser reinventado, oferecendo estruturas mais flexíveis e favoráveis para o desenvolvimento pedagógico e a aprendizagem significativa, mas também é essencial desenvolver o aluno enquanto cidadão, com base nas tão faladas habilidades socioemocionais.

A Figura 1.7 apresenta o contexto da Educação 4.0 e suas inter-relações entre diferentes habilidades e áreas da aprendizagem. Neste contexto, a inovação educacional abre espaço para a disseminação e uso de tecnologias aplicadas em diferentes segmentos como: economia digital, sala de aula, alfabetização de dados (Literacia de Dados), educação online, sistemas computacionais, learning analytics, fatores humanos, inteligência artificial, desenvolvimento sustentável, indústria 4.0, inovação social, inteligência coletiva e ciências comportamentais. Fica claro nesta ilustração e com as discussões desse capítulo, que as tecnologias e habilidades apresentadas andam de mãos dadas com a aprendizagem colaborativa.

É fato notório a necessidade por avanços de estratégias a fim de viabilizar a aprendizagem colaborativa. É notório também o surgimento de métodos de ensino e ferramental tecnológico de suporte à aprendizagem com alta carga de colaboração. No entanto, pouco se tem pensado em como preparar professores e alunos para este novo momento da educação, principalmente se pensarmos no momento atual de Pandemia e no Pós-pandemia.

\subsection{Considerações Finais}

Este texto abordou conceitos e aspectos gerais da Avanços da Aprendizagem Colaborativa com Suporte Computacional, tendo como domínio de aplicação os requisitos advindos da Educação 4.0, Métodos de Ensino e Modelos de Colaboração. Discutimos como esses requisitos ajudam a delinear o que chamamos de Educação 4.0. Neste texto, apresentamos também o framework Collab_Edu, que aponta estratégias de planejamento da colaboração em educação com o objetivo de orientar professores e alunos quanto ao tipo e dinâmica das atividades educacionais propostas, ferramentas tecnológicas e infra-estrutura necessárias para a condução das atividades e formação de grupos.

Também foram apresentados no capítulo métodos e abordagens essenciais no processo educativo, oferecendo condições de aprendizagem em contextos de incertezas. O capítulo mostrou a importância do desenvolvimento de múltiplas atividades e questionamentos sobre a informação e a autonomia do aluno para resolução de problemas complexos e de convivência em situação de diversidade. E, que mesmo em cenários remotos, como estes que estamos vivendo, foi possível desenvolver trabalhos em grupo com participação ativa.

O capítulo permitiu uma reflexão sobre a aplicação da aprendizagem colaborativa mediada por computador (CSCL) no momento que estamos vivendo, quando fomos paralisados pela pandemia: a COVID-19. Durante este período, inúmeras pessoas foram infectadas e muitas perderam suas vidas. Para mitigar esse problema, a maioria dos governos seguiram recomendação da Organização Mundial da Saúde (OMS) e adotaram alguma forma de distanciamento social. Em grande parte dos países, foi decretada suspensão de aulas, fechamento temporário de serviços não essenciais e suspensão de transportes, e foram feitas recomendações à população para que ficasse em casa. Através de estratégias pautadas na CSCL, foi possível buscar soluções e transformar o papel do 
professor e aluno. Foi possível também tornar as relações de aprendizagem mais criativa, reflexiva, crítica e cada vez mais colaborativa.

A população foi incentivada a ficar em casa, e a um só tempo, compreender e trabalhar a distância de forma distribuída, síncrona e/ou assíncrona, no formato home office e home schooling [Calado 2020, Dingel and Neiman 2020]. Ações para integrar tecnologias digitais e metodologias ativas em processos educativos foram observadas na prática. Para isso, foi preciso integrar essas ações ao processo pedagógico, pensando em uma expansão do desenvolvimento prático voltado para o conhecimento, tecnologias, linguagens, recursos, modelos colaborativos, relações sociais e pedagógicas.

As tecnologias existentes, inicialmente limitadas a grupos restritos, de repente se popularizaram. Sob stress, algumas revelaram sua vulnerabilidade e outras suas grandes funcionalidades. Muitos questionamentos sobre o ensino online e CSCL ocorreram no ano de 2020, onde suas práticas se fizeram presentes no domínio educacional. Preocupações associadas ao rendimento acadêmico dos alunos, preparo dos professores para essa dinâmica de ensino, privacidade para professores e alunos, aconteceram e continuam em processo de investigação.

O ano de 2020 será um estudo de caso e seus impactos serão apresentados nos resultados práticos e em pesquisas científicas. Esperamos que o material deste curso sirva de referência aos interessados em iniciar seus estudos em Aprendizagem Colaborativa mediada por computador (CSCL), e que sua leitura motive e incentive o surgimento de novos pesquisadores e comunidades na área.

\section{Agradecimentos}

Este Capítulo foi apoiado pela Fundação de Amparo à Pesquisa do Estado do Rio de Janeiro (FAPERJ). Juliana B. dos S. França foi apoiada pela FAPERJ no processo E26/211.367/2019.

\section{Referências}

Awidi, Isaiah T., and Mark Paynter. "The impact of a flipped classroom approach on student learning experience." Computers \& Education 128 (2019): 269-283.

Boud, David, and Grahame Feletti, eds. The challenge of problem-based learning. Psychology Press, 1998.

Bacich, Lilian, and José Moran. Metodologias ativas para uma educação inovadora: uma abordagem teórico-prática. Penso Editora, 2018.

Calado, S. (2020) "Novos modelos de trabalho? covid-19 pode ser oportunidade para testá-los", https://eco.sapo.pt/especiais/covid-19-poder-seroportunidade-para-testarnovos-modelos-de-trabalho/, Acesso 04/2020.

Costa, Joabio Alekson Cortez, Júlia Diniz de Oliveira, and Denis Rodrigues Dantas. "Metodologias ativas e suas contribuições no processo de ensino-aprendizagem." Série Educar-Volume 40 Prática Docente: 8.

Dingel, J. I. and Neiman, B. (2020) "How many jobs can be done at home?", https://www.nber.org/papers/w26948, Acesso 04/2020. 
Dunwill, E. (2016). "4 changes that will shape the classroom of the future: Making education fully technological.", https://elearningindustry.com/4- changes-will-shapeclassroom-of-the-future-making-education-fully-technological.

Ferrreira, Tais Borges, et al. "Regras para formação de grupos de colaboração utilizando detecção automática de traços de personalidade." Revista Brasileira de Informática na Educação 28 (2020): 273.

Fink, L. Dee. "Beyond small groups: Harnessing the extraordinary power of learning teams." Team-based learning: A transformative use of small groups in college teaching (2004): 3-26.

Fisk, Peter. "Education $4.0 \ldots$ the future of learning will be dramatically different, in school and throughout life." Last modified (2017).

Fuks, H., et al. Teorias e modelos de colaboração, \| Sistemas Colaborativos, cap. 2. ISBN 978-85-352-4669-8, 2011.

Garcia, A.C.B., Vieira, V., Vivacqua, A.S., França, J.B.S., Dias, A.F.S. (2020) Groupware 4.0: Avanços e Desafios da Computação Social. JAI CSBC, in press.

Hmelo-Silver, Cindy E. "Problem-based learning: What and how do students learn?." Educational psychology review 16.3 (2004): 235-266.

Hussin, Anealka Aziz. "Education 4.0 made simple: Ideas for teaching." International Journal of Education and Literacy Studies 6.3 (2018): 92-98.

Jeong, Heisawn, and Cindy E. Hmelo-Silver. "Seven affordances of computer-supported collaborative learning: How to support collaborative learning? How can technologies help?." Educational Psychologist 51.2 (2016): 247-265.

Johnson, Claire. "Team-Based Learning for Health Professions Education: A Guide to Using Small Groups for Improving Learning." The Journal of Chiropractic Education 23.1 (2009): 47.

Keengwe, Jared, ed. Promoting active learning through the flipped classroom model. IGI Global, 2014.

Laval, Christian. A escola não é uma empresa: o neoliberalismo em ataque ao ensino público. Boitempo Editorial, 2019.

Lin, Jian-Wei, and Hao-Chiang Koong Lin. "User acceptance in a computer-supported collaborative learning (CSCL) environment with social network awareness (SNA) support." Australasian Journal of Educational Technology 35.1 (2019).

Michaelsen, Larry K., and Michael Sweet. "The essential elements of team-based learning." New directions for teaching and learning 2008.116 (2008): 7-27.

Pinedo, R., N. García, and M. Cañas. "Thinking routines across different subjects and educational levels." INTED2018 (2018): 5577-5580.

Reidsema, Carl, et al. "The Flipped Classroom." Practice and Practices in Higher Education. Ed. Springer (2017).

Reimschisel, Tyler, et al. "A systematic review of the published literature on team-based learning in health professions education." Medical teacher 39.12 (2017): 1227-1237. 
Reis, Rachel, and Seiji Isotani. "Formação de Grupos em Ambientes CSCL baseada na combinação entre os Traços de Personalidade e Teorias de Aprendizagem Colaborativa." Anais dos Workshops do Congresso Brasileiro de Informática na Educação. Vol. 8. No. 1. 2019.

Savin-Baden, Maggi, and Claire Howell Major. Foundations of problem-based learning. McGraw-hill education (UK), 2004.

SCHNEIDERS, Luís A. "O método da sala de aula invertida (flipped classroom)." Lajeado: ed. da UNIVATES (2018).

Sepulveda Larraguibel, Yerko, and Juan I. Venegas-Muggli. "Effects of Using Thinking Routines on the Academic Results of Business Students at a Chilean Tertiary Education Institution." Decision Sciences Journal of Innovative Education 17.4 (2019): 405-417.

Stahl, Gerry, and Kai Hakkarainen. "Theories of CSCL." International handbook of computer-supported collaborative learning. New York, NY: Springer. Retrieved from: http://gerrystahl. net/pub/cscltheories. pdf(2020).

Stahl, Gerry, Timothy Koschmann, and Dan Suthers. "Aprendizagem colaborativa com suporte computacional: Uma perspectiva histórica." Traduzido por Hugo Fuks, Tatiana Escovedo (Português do Brasil) (2006).

Stöhr, Christian, Christophe Demazière, and Tom Adawi. "The polarizing effect of the online flipped classroom." Computers \& Education 147 (2020): 103789.

Tardelli, André, et al. "A Influência da Personalidade do Aluno na Construção de Grupos de Trabalho em Sala de Aula." Brazilian Symposium on Computers in Education (Simpósio Brasileiro de Informática na Educação-SBIE). Vol. 30. No. 1. 2019.

Trevelin, Ana Teresa Colenci, Marco Antonio Alves Pereira, and José Dutra de Oliveira Neto. "A utilização da "sala de aula invertida" em cursos superiores de tecnologia: comparação entre o modelo tradicional e o modelo invertido "flipped classroom" adaptado aos estilos de aprendizagem." Revista de estilos de aprendizaje 6.12 (2013).

Vivacqua, Adriana Santarosa, and Ana Cristina Bicharra Garcia. "Ontologia de colaboração." Sistemas Colaborativos 1 (2011).

Wolberg, Rochelle Ibañez, and Allison Goff. "Thinking routines: Replicating classroom practices within museum settings." Journal of Museum Education 37.1 (2012): 59-68.

\section{Curriculum resumido dos autores}

\section{Juliana Baptista dos Santos França}

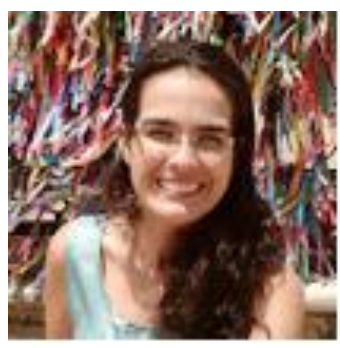


Doutora em Informática pela Universidade Federal do Rio de Janeiro (PPGI/UFRJ 2018) com ênfase em Gestão de Sistemas Complexos. Concluiu seu Pós doutorado na UFRJ na área de CSCW (PPGI/UFRJ - 2018). Mestre em Informática pelo Programa de Pós-Graduação em Informática (PPGI/UNIRIO - 2012) da Universidade Federal do Estado do Rio de Janeiro, com ênfase na linha de pesquisa Sistemas de Apoio a Negócios. Possui graduação em Sistemas de Informação pela Universidade Federal do Estado do Rio de Janeiro (UNIRIO), e também graduação em Engenharia Cartográfica pela Universidade do Estado do Rio de Janeiro (UERJ). Atualmente é Professora Adjunto na Universidade Federal Rural do Rio de Janeiro (UFRRJ) junto ao Departamento de Computação (DECOMP) e atua como colaboradora no programa de pós-graduação em informática da UFRJ com a coorientação de alunos de mestrado. É membro da ACM/FCA desde 2019. Atuou na organização de eventos científicos nacionais e internacionais como ISCRAM 2016, Summer School em IHC/CSCW 2019, e SBSC 2019. Tem experiência na área de Sistemas de Informação e atua principalmente nos seguintes temas: Colaboração (CSCW), Gestão de Conhecimento, BPM, Suporte à Decisão, CSCL e Modelagem Conceitual e Ontológica.

\section{Angélica Fonseca da Silva Dias}

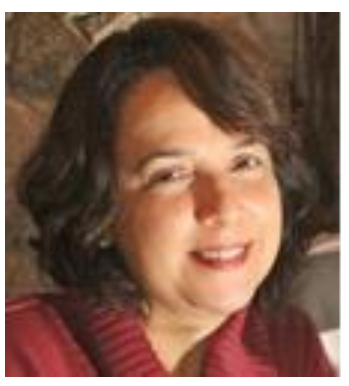

Doutora em Informática pela Universidade Federal do Rio de Janeiro com ênfase em Gestão de Sistemas Complexos. Mestre em Sistemas de Informação pela UFRJ. Especialista nas áreas de Gestão Executiva e E-Business (COPPEAD/UFRJ) e Inteligência e Database Marketing pela (NCE/UFRJ) e graduação na Unesa. Diretora da Área de Extensão e Coordenadora de Extensão do NCE/UFRJ. Foi Coordenadora acadêmica dos cursos de pós-graduação lato sensu do Instituto Tércio Pacitti/NCE, na UFRJ. Foi docente dos cursos do IBMEC e dos cursos de pós-graduação online do COPPEAD. Docente convidada nos programas de graduação e pós-graduação do Departamento de Ciência da Computação, Instituto de Economia, Escola de Engenharia - Politécnica e no Programa de Pós-graduação em Informática da UFRJ e no Programa de História, de Ciência, de Tecnologias e Epistemologia. Atua como colaboradora no programa de pós-graduação da UFRJ com a coorientação de alunos de graduação e mestrado. Atuou na organização de eventos científicos nacionais e internacionais (CBIE 2012, ISCRAM 2016, SBSC 2019 e WCO 2020). Tem experiência nas áreas de Administração Pública, Gerência de Projetos, Ciência da Computação e Educação. Temas de interesse: Gestão de Conhecimento, Trabalho e Aprendizagem Cooperativa apoiada por computador (CSCW e CSCL), Tecnologia Assistiva, Economia Circular, Sustentabilidade, Gestão Estratégica da Informação, Inteligência Coletiva, Inteligência Ambiental, Data Literacy e Educação a distância. 


\section{Marcos Roberto da Silva Borges}

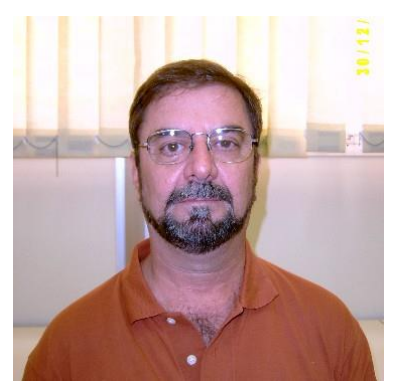

Professor Titular aposentado do Departamento de Ciência da Computação do Instituto de Matemática da Universidade Federal do Rio de Janeiro desde 2011. Desde fevereiro de 2020 é Investigador Senior do TECNUN, Universidade de Navarra, Espanha. Possui graduação em Engenharia Elétrica pela UFRJ (1975), mestrado em Engenharia de Sistemas e Computação pela COPPE/UFRJ (1981) e doutorado em Sistemas de Informação - University of East Anglia (1986). Realizou pós-doutorado na Santa Clara University (1994-1996). Em 2001 atuou como Professor Visitante da Universidade de Paris VI e entre 2004 e 2005 na Universidade Politécnica de Valencia, Espanha. Atua como pesquisador do Programa de Pós-Graduação em Informática da UFRJ. Tem experiência na área de Ciência da Computação, com ênfase em Sistemas de Informação, atuando principalmente nos seguintes temas: sistemas colaborativos, gestão de conhecimento, engenharia de software e projetos de interfaces. Mantém cooperação regular com professores de: Universidade Politécnica de Valencia, Espanha, Ohio State University, EUA e o Rensselaer Polytechnic institute, EUA. Coordenou a organização do Congresso da SBC em 1988. Foi um dos fundadores do grupo de interesse em Engenharia de Software e do grupo de interesse em Sistemas Colaborativos, ambos da Sociedade Brasileira de Computação. Foi um dos fundadores do CRIWG (Collaboration Researchers International Working Group) e membro do Conselho de Administração de 1995 até 2012. É membro do Conselho de Administração da IEEE-CSCWD e do ISCRAM. Em 2016 organizou XIII edição da Conferência Internacional sobre Sistemas de Informação para a resposta e gestão de crises (ISCRAM 2016). Foi Co-Chair do Comitê de Programa da Conferência ACM CSCW em 2017. Foi Presidente da ISCRAM (Information Systems for Crisis Response and Management) Association.entre 2018 e 2019. Bolsista de Produtividade em Pesquisa 1-D do CNPq (2016-2020) e Cientista do Nosso Estado da FAPERJ (2018-2020). 